\title{
Journal of Scheduling (2018)
}

\author{
Edmund Burke $^{1} \cdot$ Michael Pinedo $^{2}$
}

Published online: 8 February 2018

(c) Springer Science+Business Media, LLC, part of Springer Nature 2018

The Journal of Scheduling enters its 21st volume and we approach the 20th anniversary of our launch. The very first issue of the Journal was published in June 1998 and that first volume had just three issues. The Journal has come a long way in those 20 years but some things have remained unchanged. We are still committed to inter-disciplinarity and to publishing research papers of the highest quality. The Journal has always aimed to be broad in its scope and to cover a wide range of theoretical problems and real world applications. We encourage authors to submit review and survey papers and we continue to support special issues focused around specific themes or revised and selected papers from appropriate conferences and workshops. Indeed, in 2017, we published a special issue of papers presented at the Twelfth Workshop on Models and Algorithms for Planning and Scheduling Problems (MAPSP2015), which was held in La Roche-en-Ardenne, (Belgium) in June 2015. The Guest Editors of this special issue were Yves Crama, Dries Goossens, Roel Leus, Michaël Schyns, and Frits Spieksma.

During the last year, our journal has performed well according to a variety of metrics. In the SCImago Journal and Country Rank, the Journal of Scheduling is highlighted against four different categories: Artificial Intelligence, Engineering (Miscellaneous), Operations Research and Software. Our journal is ranked in the top quartile for all four categories, which reflects its inter-disciplinarity and its strong international profile. Our current Thompson Reuters impact factor is 1.281. The number of downloaded articles between January and November 2017 was 44,211 (the figure for December was not available at the time of writing). During 2017, we had 226 new submissions. The current acceptance rate is approximately $25 \%$.

The average time that it has taken to turn around submissions (i.e. the time taken between submission and first decision) has improved. In 2016, we reported a figure of 73 days. For 2017, the average time was 68 days, a little more than 2 months. We are committed to working towards improving this further.

We normally close this Editorial by offering our thanks to all those who have contributed to the Journal's success. This year, we would like to focus on everyone who has contributed over its twenty year lifetime. This includes Editors, Associate Editors, Authors, Reviewers, and staff from our three publishers: Wiley, Kluwer and Springer. We would like especially to remember the contribution of David Ireland at Wiley, particularly during 1997 and 1998. The Journal would never have existed without his commitment to its vision. We would like to offer another very special thank you to Gary Folven, who took the Journal to Kluwer in 2003. His support for the Journal was very strong and the Journal has continued to benefit from his contribution. Springer acquired Kluwer and the Journal of Scheduling had its third publisher. The editorial team at Springer has been a pleasure to work with. We are particularly grateful to Ramya Murali, Bharathi Ramachandran, Faith Su, Matthew Amboy and Neil Levine. During 2017, we said goodbye to Venkat Ganesan. We would like to say thank you to him for all his work.

We are proud of what the Journal has achieved over the last 20 years and we look forward to the future.

$凶$ Edmund Burke

ekb@qmul.ac.uk

1 London, UK

2 New York, NY, USA 